\title{
Generic Modular Ontology for Innovation Domain. A Key Pillar Towards "Innovation Interoperability"
}

\author{
Lamyaa EL BASSITIP
}

\begin{abstract}
In a century of complexity, organizations are moving towards open innovation. So, contemporary Innovation Management Systems have to deal with the distributed, heterogeneous and fast growing characteristics of knowledge that are available in different forms and are rather weakly structured. In addition, the increasing degree of specialization and interdependence between and among organizations calls for group capabilities at the organizational level to interoperate with others to produce not only novel, but also critically acclaimed innovations. This is the focus of this paper that introduces the new concept of "Innovation Interoperability". Then, it formalizes and represents semantically the key concepts underlying a systematic innovation approach and the relations between them, through a Generic Modular Ontology, we have called "GenID Ontology". The latter consists of three interconnected subontologies, referring to the key dimensions of successful innovation within an open context, which are: Core-ideas, Actors and Context. This paper has adopted a mixed research strategy and uses a qualitative online survey to examine the delivered constructs.
\end{abstract}

Keywords: innovation interoperability; idea and innovation management; ontology; semantics; online survey.

\section{INTRODUCTION}

The need to develop innovations quickly and systematically has become the key driver of growth today. To be able to do that organizations have to make

1 Innovation Interoperability: A new concept that aims to smartly investigate experiences as well as inter- and intraorganizational interactions and critically exploit the deduced knowledge to meet current needs and develop new opportunities for unforeseen circumstances.

2 Lamyaa EL BASSITI, Ph.D. Student, ENSIAS, Mohammed V University in Rabat, Morocco, Avenue des Nations Unies, Agdal, Rabat Maroc B.P:8007.N.U, e-mail: elbassitilamyaa@gmail.com. 
best use of their knowledge resources and memory. So, there is an imperative to actively use previous, similar, as well as equal, purposive experiences to advance new ideas' and opportunities' emergence. Thus, keeping a record of previous innovation initiatives appears to be of utmost importance as part of the innovation process. As such, every formalized innovation event has to be collected and stored as experienced knowledge, and any technology able to do this will allow the innovation process performance to be improved by reducing innovation time, as well as avoiding repetition and duplication in the process. Besides, organizations have become more aware of external knowledge and technology and they feel a growing need to open up their innovation processes.

Nevertheless, the widely distributed, heterogeneous and fast growing characteristics of innovation knowledge available in different forms and rather weakly structured, make it more difficult to find, organize, access and maintain relevant sources of knowledge. So, it becomes imperative to integrate the innovation process with mechanisms and technologies that allow the establishment of a common vocabulary to facilitate access and reuse of knowledge, and to coordinate efficiently the actors' roles in the innovation process. This is an explicit call to the concept of "interoperability". Zittrain (2008) has argued that ideas which emerge within an interoperable context are likely to be good because it could lead to "generative" innovations. Nevertheless, at this level the main challenge is to identify "innovation interoperability" and what it means, the key dimensions underlying this concept, their potential benefits and how it can be achieved and sustained within a complex system.

Pagano et al. (2013) distinguished three levels of interoperability: (1) "Organizational level" entailing the definition of processes and policies to enhance inter and intra-collaboration; (2) "Technical level" involving the link up of heterogeneous systems via agreed standards; (3) "Knowledge level" focusing on the exchange and sharing of data and its meaning between linked systems. One of the most complicated issues related to knowledge interoperability is "knowledge representation". Hence, it is necessary to create a structure able to take knowledge from day-to-day formal innovation events, to store proper characteristics of the experience acquired through these activities, to keep this experience as explicit knowledge, and to make it available for tools and technologies in order to be used, analyzed, and categorized. In doing so, it could be possible to extract the most significant characteristics from the current circumstances and relate them to similar situations and initiatives in the past. This paper focuses on this issue and aims to provide a relevant answer to the following research question: "How 
to represent the innovation domain semantically to support innovation interoperability?"

The remainder of this paper unfolds as follows: In the next section, to facilitate a better understanding of the topic, we introduce the concept of "innovation interoperability" and highlight the need for it within an open context. Then we review and discuss the existing innovation ontologies. The following section presents the adopted research design and evaluation approach. Next, we detail "GenID Ontology" aiming to deliver a single point of reference for innovation KM and provide a formalization that can be applied to achieve interoperability within and across different organizations and knowledge systems. Data collection and analysis of the empirical investigation are presented in the following section, before we conclude by summarizing topics for further research.

\section{LITERATURE REVIEW}

\section{The need for "innovation interoperability"}

Over the last two decades, innovation management has increasingly evolved towards a more distributed, more participatory and more decentralized approach to innovation. Thence, organizations have become more aware of external knowledge, technology and competencies to maintain their competitiveness in the global market. Named "Open Innovation", this paradigm refers to the use of both inflows and outflows of knowledge to improve internal innovation and expand the markets for external exploitation of innovation (Chesbrough, 2003).

Recently, the interest in open innovation has been on the rise in both the academic and business world. A report authored by Chesbrough and Brunswicker (2013) found that an impressive $78 \%$ of large companies are practicing some form of open innovation and that they are satisfied with the achieved results. A 2015 study conducted by Accenture with G2OYEA highlighted that $26 \%$ of large companies currently practiced open innovation, while a further $38 \%$ expect to within the next three years.

Being based on the fact that useful knowledge today is widely distributed, weakly structured, heterogeneous and grows very quickly, open innovation challenges traditional notions of KM. So, within an open context there is a clear need for some sense of what of the available knowledge resources should be mapped. Further, more and more innovation systems appear, so it becomes imperative to establish a common vocabulary that facilitates access and reuse of knowledge and to coordinate efficiently the actors involved in the innovation process. In other words, there is a need for innovation 
interoperability (El Bassiti \& Ajhoun, 2014). The EU Software Directive (2009) defines interoperability as the ability to exchange and mutually use information. Pagano et al. (2013) regards interoperability as "a problem affecting the interaction of entities at various levels". Accordingly, we define "innovation interoperability" as the ability of people, systems and organizations to smartly investigate experiences as well as inter- and intra-organizational interactions and critically exploit the deduced knowledge to meet current needs and develop new opportunities for unforeseen circumstances. Thus, storing experiences is necessary for finding an optimal path to the source of inspiration required for the emergence of great ideas and outstanding innovations. To deal with such a challenge, semantic technologies have been proposed to provide an efficient solution to support the integration of the innovation process with heterogeneous knowledge sources.

According to Gruber (2007) "many major scientific discoveries and breakthroughs have involved recognizing the connections across domains or integrating insights from several sources. These are not associations of words; they are deep insights that involve the actual subject matter of these domains. The Semantic Web has the machinery to help address interoperability of data from multiple sources". In May 2001, the concept of a semantic web was introduced by Berners-Lee et al. as a collection of standards and approaches for bringing order and meaning to unstructured data on the web. Semantic web technologies enable the explicit representation of knowledge and its further processing to deduce new knowledge from an implicitly hidden one. In addition, using semantic techniques in innovation management has the potential to improve end-user efficiency by means of automated processing and to cope with the advanced analytical processing of innovation metadata through reasoning. Thus, innovation managers can profit from better structured information, integration and data exchange across tools and platforms, as well as additional semantic reasoning capabilities that would allow them to analyze ideas based on related concepts. To achieve these goals, ontologies, which provide "formal and explicit specification of a shared conceptualization" (Studer et al., 1998), were used.

Ontologies, as the foundational component of semantic technologies, provide a framework for the "standardization of concepts and relationships used to describe and represent an area of knowledge", in order to support interoperability and facilitate access and reuse of knowledge (W3C). They encapsulate rules for automated inference and reasoning, making it possible for applications and software agents to discover relationships and meaning which are not explicitly expressed (Berners-Lee et al., 2001). In addition, using ontologies can benefit innovation management by allowing advanced searches, information filtering and semantic annotation, which can support 
continual learning, enhance the understanding of contributions from different actors and increase the quality of decision-making.

\section{Innovation ontologies}

According to Lee (2001) "research in the IS field examines more than just the technological system, or just the social system, or even the two side by side; in addition, it investigates the phenomena that emerge when the two interact". Thus, to understand the innovation field, an ontology that links the natural, the social and the artificial worlds of human constructions is required. Although several research-works currently deal with innovation management, to our knowledge few of them explicitly aim at creating a common ontology for the purpose of achieving interoperability. An overview of the existing semantic models has been summarized in Table 1 below:

Table 1. Overview of innovation ontologies

\begin{tabular}{|c|c|}
\hline Ontology & ure \\
\hline $\begin{array}{l}\text { ogy (Ning } \\
2006)\end{array}$ & $\begin{array}{l}\text { - Classified as Domain Ontology } \\
\text { - Designed for Extended Enterprise } \\
\text { - Facilitates distributed collection and development of ideas } \\
\text { - Relies on Semantic Technologies to allow integration of idea } \\
\text { development tools } \\
\text { - Main Classes: Goals, Actions, Teams, Results and Community }\end{array}$ \\
\hline $\begin{array}{l}\text { OntoGate } \\
\text { Ontology } \\
\text { (Bullinger, } \\
\text { 2008) }\end{array}$ & $\begin{array}{l}\text { - Classified as Domain Ontology } \\
\text { - Focuses on the early stage of innovation. } \\
\text { - Aimed at modeling the idea assessment and selection rather than } \\
\text { providing technical integration } \\
\text { - Deduced from empirical research } \\
\text { - Covers three perspectives along which an idea or concept can be } \\
\text { evaluated: market, strategy and technology } \\
\text { - Presents a large number of modules } \\
\text { - Core Elements: Participant, Gate (integrates Assessment), Input, Output }\end{array}$ \\
\hline $\begin{array}{l}\text { Idea Ontology } \\
\text { (Riedl et al., } \\
\text { 2009) }\end{array}$ & $\begin{array}{l}\text { - Classified as Application Ontology } \\
\text { - Designed for Service Sector } \\
\text { - Focus on the front end of innovation (Idea Management) } \\
\text { - Offers common language for idea storage and exchange to achieve } \\
\text { interoperability across innovation tools } \\
\text { - Does not provide a data model for representing individual ideas } \\
\text { - Provides a technical means to represent complex idea evaluations } \\
\text { along various concepts } \\
\text { - Main Concepts: Core Idea, Idea Realization, Community, Status } \\
\text { - Generic Concepts of Core Idea: Origin, Person (Creator), Rating, Tagging, } \\
\text { Grouping }\end{array}$ \\
\hline
\end{tabular}




\begin{tabular}{ll}
\hline Ontology & Feature \\
\hline & - Classified as Domain Ontology \\
& - Focus on the front end of innovation (Idea Management) \\
GI2MO & Aimed at serializing the IT systems data and enabling idea comparison \\
Ontology & regardless of the underlying IT system layer \\
(Westerski et & - Aimed at using semantic web technologies to interconnect data \\
al., 2010) & - Developed based on a defined Idea Management Life Cycle \\
& Provides a formalization of metadata that can be used to describe ideas \\
& and associated information \\
& - Main Concepts: Trigger, Innovation, Object, Proposed \\
\hline
\end{tabular}

Source: El Bassiti \& Ajhoun (2014).

As a stored experience, we consider every innovation deliverable as a "unique knowledge unit" involving a "similar set of activities". This uniqueness, on one hand, is driven by multiple factors including the transient nature of innovation actors and the distinctive characteristics and contextual criteria of each innovation journey. The similarity, on the other hand, is driven by long-held views of how innovation initiatives should be conducted through reasonably stable organizational structures, slow-changing key concepts and a risk-averse approach to investment policies. This challenging duality of uniqueness and similarity can be addressed through the development of a granular ontology that has to be based on the concept of flexibility to cater for uniqueness and the notion of uniformity to cater for similarity.

Accordingly, a generic representation of innovation must cover the following criteria: (1) Management Flexibility, which allows checking if semantic tools can be applied irrespective of organizational characteristics or contextual variables, (2) Validation Uniformity, which allows checking if the innovation deliverables are evaluated based on a set of predefined criteria. As well, if the assessment results pertaining to an innovation phase, stage or iteration can be uniformly and respectively compared to another deliverable at the same phase, stage or iteration. In addition, according to Fox et al. (1998) and Gruber (1995), a representation of innovation must also cover (3) Functional Completeness, which allows checking if the semantic representation provides the necessary information to support the management of the represented domain, i.e. if the semantic representation is in respect to the domain's purpose and its intended use. (4) Perspicuity, which allows checking if the representation is easily understood by the users so that it can be consistently applied and interpreted, and if it "documents itself?" (5) Precision/Granularity, which allows checking if the core set of the representation primitives are partitionable or do they overlap in meaning? In other words, does the representation support reasoning at various levels of abstraction and detail? Based on these factors we evaluated the innovation 
ontologies presented in Table 1 above. Table 2 below provides a summary of this evaluation:

Table 2. Innovation ontologies evaluation

\begin{tabular}{|c|c|c|c|c|c|}
\hline Ontology & $\begin{array}{l}\text { management } \\
\text { flexibility }\end{array}$ & $\begin{array}{l}\text { validation } \\
\text { uniformity }\end{array}$ & $\begin{array}{l}\text { functional } \\
\text { completeness }\end{array}$ & perspicuity & $\begin{array}{l}\text { precision/ } \\
\text { granularity }\end{array}$ \\
\hline $\begin{array}{l}\text { Iteams } \\
\text { Ontology }\end{array}$ & $x$ & $x$ & $x$ & V & v \\
\hline $\begin{array}{l}\text { OntoGate } \\
\text { Ontology }\end{array}$ & V & v & $x$ & $x$ & $x$ \\
\hline $\begin{array}{l}\text { Idea } \\
\text { Ontology }\end{array}$ & $x$ & $x$ & $x$ & $v$ & v \\
\hline $\begin{array}{l}\text { GI2MO } \\
\text { Ontology }\end{array}$ & V & v & $x$ & $x$ & v \\
\hline
\end{tabular}

The investigation of the concept innovation has been a hard challenge for scholars because the definition of this concept is still fluid and slippery. The literature from innovation semantic representation provides few ontologies which, although relevant, have limited the scope of the key concepts underlying the innovation knowledge area. Each of these ontologies has presented "innovation" differently to suit the purpose of the study at hand, which has led to narrow and restricted conceptualizations of this domain of knowledge on the majority of ontologies. In addition, the presented models - although valuable in their own right - do not provide a foundational basis suitable for the systematic investigation of the innovation domain. Because of this inconsistent representation of innovation, no common understanding exists about what the meaning is of many related concepts, which has led to problems for both academics and practitioners in the field of innovation management as there is little opportunity to build up a shared knowledge model about innovation.

Although relevant, the knowledge representation provided by Iteams Ontology investigates the organizational context (Extended Enterprise) and provides the key features of organization that interact with and affect the innovation process, but doesn't provide the key concepts underlying innovation as an activity and a knowledge domain. OntoGate, although it is considered as domain ontology, doesn't highlight any specific concept related to the innovation knowledge domain. Further, it provides a very generic overview of the key elements of the innovation process and lacks the explicit capturing of specific concept related to the idea which is the central object that defines an innovation, the context where this idea has emerged 
and evolved, and the actors involved in the innovation process. Whereas Idea Ontology is designed for the service sector, it emphasizes a set of concepts related to idea generation and focuses on the concepts underlying idea evaluation. Finally, GI2MO Ontology, despite providing coverage for most of the key concepts underlying idea management, focuses on idea assessment and lacks explicit capturing of contextual conditions and knowledge about actors involved in the innovation process.

As a result, we conclude that the presented ontologies, although they have a similar objective to represent innovation semantically, they differ in conceptual depth, practical focus, terminology, and target audience. Each model is either specific to a domain or focuses mainly on a specific aspect of the innovation process. Although there are a few -extensive- efforts trying to provide a specific view, there is no comprehensive model that can be applied to the innovation knowledge modeling, its lifecycle phases or its deliverables in a holistic manner. As such, we decided to design and develop a generic ontology to represent semantically the innovation domain in a systematic and consistent manner, in order to avoid the shortcomings and weaknesses found in existing models. Leveraging from existing ontologies (e.g., FOAF, DOAP, SIOC, SKOS, SCOT), we aim to define a more targeted approach to innovation design and adoption with a systematic and open view (El Bassiti et al., 2017).

\section{RESEARCH DESIGN}

According to Louis Pasteur "chance favors the prepared mind". Since this research work does not seek to prove, disprove or compare phenomena but rather to discover the underlying structures of a nascent domain of knowledge, this study adopted a mixed research perspective combining behavioral and design research patterns, an interpretive and critical paradigm, a mixture of research strategies focusing on retroduction, and an exploratory mixed data collection methodology.

The components underlying the GenID framework were first submitted for scrutiny through peer-reviewed publications. Then, they were presented to subject matter experts through an online survey (questionnaires and interviews). Next, the collected data were analyzed and the results have been further examined through critical discussions within the research group as well as with other innovation professionals. In addition, we collected relevant documentation from key databases (e.g., EBSCO, Elsevier and Thomson Reuters) to complement the data collected through the survey. 
To represent a subset of potential stakeholders, a set of 16 innovation professionals and experts from both academia and industry across four countries (UK, Malaysia, Australia and US) were invited to participate in the online survey. Although they shared their materials and thoughts with us, they did not give us permission to disclose their identity.

\section{Generic Innovation Designing -GenID- Ontology}

The unpredictability of an emergent process means that it is nearly impossible to know in advance the different actors who may be involved in the process and the context of their participation (i.e. when and where they will be called in, and whether internal or external conditions will be implicated). This is because an emergent process often requires high-level professional and technical personnel; and the actors involved in such a process have a high degree of autonomy, to the extent that it is very difficult to know how and why their work is performed. In addition, in emergent processes, the needed knowledge evolves dynamically and must often be searched from distributed sources that are sometimes poorly structured and thus difficult to capture and share. Furthermore, a great deal of intuition and sense-making is required in emergent activities.

Innovation, being an emergent process, is then characterized by highly unpredictable potential actors, dynamic and not always known context conditions, and ill-structured and distributed knowledge objects. So, innovation, that is perceived as an emergent knowledge activity, refers to an organizational activity pattern characterized by (1) Emergent "context" with no predefined identity, properties or behavior; (2) Emergent "actors" with unpredictable roles or prior knowledge; (3) Emergent "knowledge objects" with no best structure or sequence. Based on these cornerstones we elicit the three key dimensions required to build a domain vocabulary to represent the innovation concept, we called "Generic Innovation Designing -GenIDOntology" (see Figure 1), which are: (1) Innovation Actor which refers to the involved individuals, organizations or communities in the innovation effort; (2) Innovation Core-Idea which refers to the aggregation of knowledge objects delivered and used by an innovation actor to generate an idea; (3) Innovation Context which refers to the contextual variables -either internal or external- impacting the innovation process (e.g. resource endowments, customer needs).

Based on this conceptualization, we identify the main challenge facing today's organizations as being able to bring "the right core-idea to the right actors in the right context". Schumpeter, the father of innovation, has argued that innovation rarely involves a single idea, but rather a bundle 
of knowledge that is brought together into a whole; in other words, most innovations are not novel in themselves but they are novel combinations of elements that already exist (Salter \& Alexy, 2013). Thus, dealing with the main challenge facing today's organizations requires seamless connections among "knowledge objects" being the innovation cores, "innovation actors" being the innovation engines, and the "innovation context" conditions being the nursery of innovation. Such connections are required to support the emergence of vibrant communities that can exchange and effectively use the full range of data, information, knowledge and wisdom. The following subsections will present each of these three dimensions as an ontology module that can fit together with other modules into an overall ontology-as depicted in Figure 1- to guide the effective and efficient management of innovation.

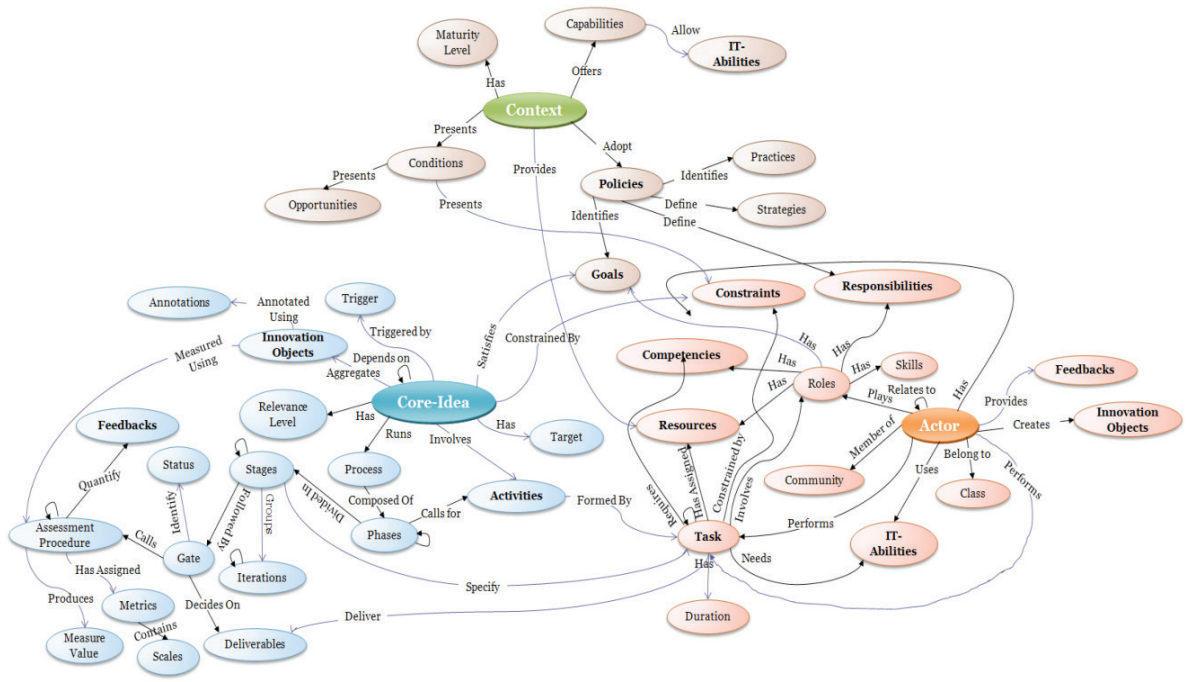

Figure 1. GenID Ontology main concepts

\section{GenID Actor Sub-Ontology}

It is often said that an innovative idea without a champion gets nowhere. According to Kozioł-Nadolna (2016) an innovation is "the result of numerous, complex interactions among units, organizations and the environment in which they operate". Human capital as a "key ingredient to organizational success and failure" (Baron \& Kreps, 1999), and by all accounts increasingly important, has become the innovative organization's most vital resource. When an innovative idea is expressed to others, it proliferates into multiple ideas because people have diverse skills, energy levels, frames of reference and interpretive schemas as a result of their backgrounds, experiences, and 
activities that occupy their attention and that filter their perceptions. These differing perceptions and frames of reference are amplified by the proliferation of transactions and relationships among people and organizational units that occur, as the innovation unfolds. In addition, motivated teams, composed of individuals with diverse expertise and experiences, usually accomplish much more than individual employees. Hence, effective management of intra- and inter-organizational interactions is critical to ensure sustained innovation capacity.

In the realm of a GenID perspective, we broadened the notion of "human capital" and we adopted the term "GenID Actor" to denote an individual, organization or a community involved in the innovation effort: "Individual", as the primary unit in understanding the organizational innovativeness capability, refers to a person who participates in the emergence, design and adoption of an idea in order to contribute to private as well as global wealth creation, which is necessary for organizations to thrive in the long run (e.g. educator, design professional, manager or a tradesman). "Organization" refers to a complex assemblage of individuals and their interactions (e.g. responsibilities, dependencies, social structures, organizational entities, objectives, tasks and resources). "Community" refers to a purposeful cluster of individuals or organizations, temporarily bound together through a unifying long-term mission, a common goal or a shared activity (e.g. CoP).

From a semantic standpoint, the GenID Actor sub-ontology aims then to represent the different kinds of innovation actors (individual, organization or community) and their interactions within the innovation process, in order to support effective management of their involvement. This sub-ontology seeks to allow the analysis of the innovation actor competencies; selecting and hiring qualified actors; assigning suitable roles to the proper actors who assist in obtaining appropriately focused communities as required in each phase, stage or iteration throughout the innovation process; exchanging frequent feedback related to goal attainment; and linking between the actors' abilities, recognition, rewards and the organization's profitability. Figure 2 below depicts a knowledge view that summarizes the main concepts, attributes and relations comprised in the innovation actor sub-ontology.

As particular concepts included in this sub-ontology we can note: (1) "Role Concept" which allows defining prototypical activities that an actor may play, alone or within a community, in order to achieve a set of predefined goals, according to the responsibilities and competencies he has. (2) "Competencies Concept" which refers to the flows of tasks for acquiring and using new innovation objects (knowledge objects) to bring new ways of thinking through progress tracking, feedback interpreting and the analysis and provision of resources needed to perform an activity. (3) "Activities 
Concept" which describes the required tasks to be performed by a given actor to achieve a defined goal using one or a set of core-ideas at a particular iteration in the innovation process.

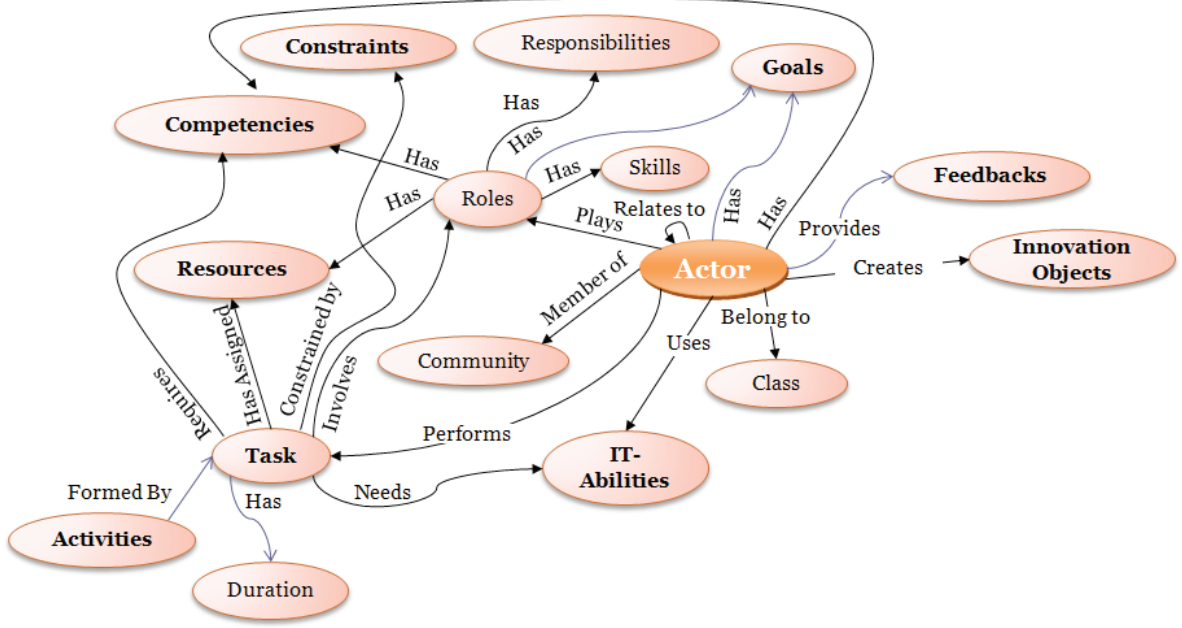

Figure 2. GenID Actor Sub-Ontology Knowledge View

\section{GenID Core-Idea Sub-Ontology}

As reported by Amabile et al. (1996) "all innovation begins with creative ideas", and they define innovation as "the successful implementation of creative ideas within an organization". As well, in the innovation process, the stage of "idea generation" also called "ideation", whose objective is individual or collective identification of new ideas or opportunities, is often recognized as one of the highest leverage point for an organization. So, ideas are a cornerstone of innovation management and are essential because without ideas, or rather without good ideas, there are few chances to have an innovation that can drive the growth of the organization. To routinely generate valuable innovative ideas requires intentionality. According to Cañibano et al. (2006) intentionality is the will to conceive or imagine realities which differ from the perceived realities with the purpose of making them effective. However, even though getting "better" is important when organizations have reached their limit of efficiency, being "different" is a matter of life and death (May, 2007). According to Davila et al. (2006), only challenges and surprises, in other words the ability to innovate sustainably and radically, can move an organization forward in our increasingly nonlinear and complex world.

Deep change has been always connected with reflection of deep assumptions and stepping out of a core of reference, which involves going beyond the boundaries of the pre-structured space of knowledge and 
reframing it in the sense of constructing and establishing new dimensions and new semantic categories. In the realm of a GenID perspective, we expanded the concept of "idea" and we used the term "GenID Core-Idea" to denote the very essence, the heart, the very meaning, the substance and the complete set of knowledge objects underlying the idea of an innovation. Revealing the core-idea of an innovation involves excavating the most profound meaning and essence of the related phenomenon by observing it closely in a highly mindful manner, asking deep questions and trying to get as close as possible to the object of investigation both intellectually and physically. Thus, an essential challenge for the innovation community has been how to represent the core-idea of an innovation in a systematic manner to realize effortless interoperability and knowledge reuse.

Researchers have proposed that the content of KMSs should be oriented around small knowledge units coupled with associated metadata and semantics (Kolovski \& Galletly, 2003). As such, GenID core-idea can be represented as one or an aggregation of the four following "Innovation Objects": (1) "Entity": a set of knowledge objects that can be used, re-used or referenced during the innovation lifecycle. (2) "Behavior": a set of actions performed by an actor on a particular entity. (3) "Process": a set of activities occurring within a given context as a result of transforming inputs into outputs in a defined order. (4) "Class": a set of qualitative or quantitative descriptions of an entity, behavior, or process. These innovation objects can be grouped into larger collections of innovation objects, which make it possible to personalize the innovation content individually to each actor's needs and perception without big investments. The short period of time that an actor needs to get acquainted with an innovation object will make the open innovation paradigm more accessible, and allow the realization of anytime-anywhere innovations. The reusability of these objects allows, thus, each actor to better understand the innovation materials and the interlinking between the different entities, behaviors, processes and classes.

From a semantic perspective, GenID Core-Idea sub-ontology aims then to represent the conceptual and practical knowledge usable by an innovation actor to perform a set of tasks in order to deliver a noteworthy outcome. This sub-ontology seeks to allow the easy handling and quick locating of relevant innovation items; breaking individual as well as organizational innovation content down into small chunks, so each innovation object can be used independently and (re)used efficiently in various innovation contexts; and providing self-contained components aggregating all the required information, so they can be easily understood, computationally searched and then quickly modified according to the innovation actor's requirements. This micro-based approach is legitimate as we suggest that any innovation can be 
built from reusable components of cognition, which are created just once, but can be used several times separately in different contexts. Such an approach can foster motivation for innovating in a sustainable manner. Figure 3 below depicts a knowledge view that summarizes the main concepts, attributes and relations comprised in the innovation core-idea sub-ontology.

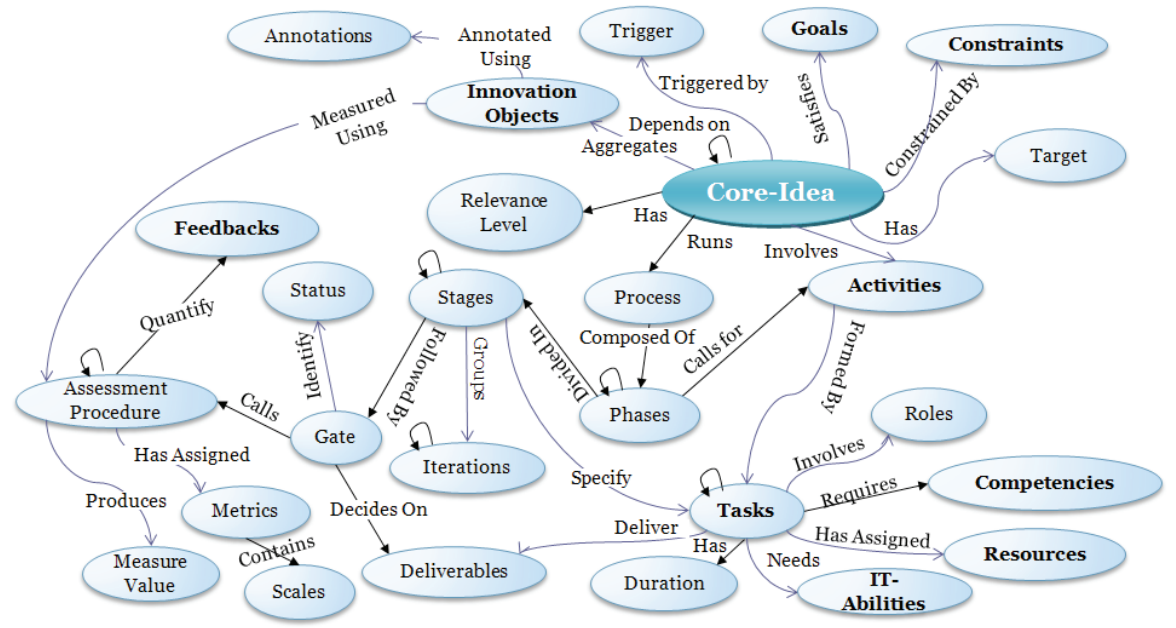

Figure 3. GenID Core-Idea Sub-Ontology Knowledge View

As particular concepts included in this sub-ontology we can note: (1) "Trigger Concept" which describes events leading to the core-idea generation. (2) "Process Concept" which allows defining task and activity networks organized in phase, stages and iterations in order to delineate the transformation of an idea into a successful innovation. (3) "Deliverables Concept" which denotes the outcome of a stage along the innovation lifecycle.

\section{GenID Context Sub-Ontology}

According to Griffin (1997), the most successful innovative companies do not succeed merely by using one innovation approach more extensively or better, but by carefully selecting the right approach within a given context. The context of innovation is not just about individual factors or organizational factors; instead, it shall integrate the various internal as well as external contextual factors into a managerial framework (Ortt \& van der Duin, 2008). A contextual approach to innovation management and a better understanding and management of such an approach can provide an overview of alternative choices in different contexts, and assist innovation actors in their decision- 
making process, which in turn will make the innovation management more efficient. Managers therefore face the challenge of creating contextual conditions where innovation actors can develop and exploit their innovative potentials (De Spiegelaere et al., 2012). Nevertheless, innovation actors must have the required abilities (e.g. freedom) to perform such adaptations, and not be constrained by corporate rules regarding innovation that contradict what their specific context demands.

In the realm of a GenID perspective, we used the term "GenID Context" to denote a network of relationships between the innovation actors' roles, inside and outside the organizational context, and the innovation objects underlying the core-ideas of an innovation. Lawson and Samson (2001) argue that a successful innovation is based on a set of core elements and processes that are similar across industries and organizations. Accordingly, as a basis for a wider conceptualization of an innovation context, we identified three fundamental elements that emphasize systematic change and sustain recreation of worthy wealth, and determine what kind of innovation strategy and deliverables an organization can adopt or produce: (1) "Resources" that refer to a set of tangible and intangible assets, in particular intellectual assets, supporting the accomplishment of innovation activities. (2) "Policies" that refer to the principles, rules and moralities guiding the decision making along the innovation lifecycle. (3) "Capabilities" that refer to the systematic knowledge practices and tools, in particular technologies, turning organizational vision into action and enhancing the organizational innovation performance.

From a semantic viewpoint, GenID Context sub-ontology aims then to represent the organizational abilities allowed to innovation actors to perform innovation activities and deliver noteworthy outcomes. This sub-ontology seeks to allow the representation of contextual ability within a wider perspective that is not only restricted to the use of technologies but that can also pertain to the development of novel policies and organizational resources. This is supported by the fact that in a turbulently and unexpectedly changing environment, the ability of an organization to change and improve organizational resources, policies and capabilities in a flexible and agile manner is a key driver of organizational performance and would impact organizational sustained competitiveness. Thus, the development of a contextual ability to be endowed with the adequate resources, appropriate policies and advanced capabilities, in order to attain breakthrough innovations seems to be more critical for systematic innovation management. Figure 4 below 
depicts a knowledge view that summarizes the main concepts, attributes and relations comprised in the innovation context sub-ontology.

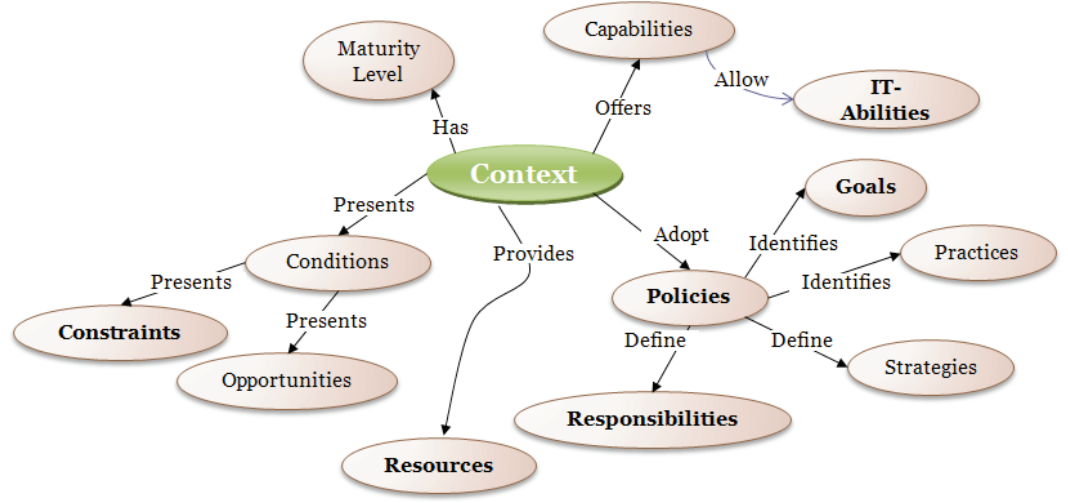

Figure 4. GenID Context Sub-Ontology Knowledge View

As particular concepts included in this sub-ontology we can note: (1) "Resources Concept" which describes the organizational assets to be allocated to an innovation actor's role for disposition under its responsibility to carry out certain activities. It may also be the result of other activities through the innovation process. It seeks to support decision making by assigning the right resource to the right actor. (2) "Capabilities Concept" which represents the organizational abilities granted to an innovation actor to continuously transform knowledge and core-ideas into new and valuable deliverables for the benefit of the entire community of stakeholders. (3) "Policies Concept" which represents alliance-based or risk-sharing contractual agreements between involved innovation actors along the innovation lifecycle. It seeks to allow the analysis of contracts, regulations and practices in order to understand how different strategies and levels of governance are working and in what way they give rise to conflicting goals and contradictory (or complementary) initiatives. It is intended to assist policy makers, researchers and community practitioners in planning strategies, preparing practices, delivering documents, distributing benefits, allocating risks and minimizing conflicts between innovation actors.

\section{EMPIRICAL INVESTIGATION}

The evaluation of ontologies is an emerging field; however, researchers have identified a number of evaluation methods that have been discussed in numerous publications. Peffers et al. (2007) distinguished two activities in the evaluation process, the first aims to show that the artifact feasibly works to 
achieve its objective in at least one context, while the second considers how well the artifact provides a solution to a problem (Venable et al., 2012). The methods for evaluation identified in this case include, for instance, surveys, simulations and logical proofs. Venable (2006), in turn, identified two methods which are the artificial evaluation that explores an artifact in a contrived and non-realistic way, and the naturalistic evaluation that is empirical and investigates the performance of an artifact in a real environment (Helfert et al., 2012). The former includes methods such as laboratory experiments, field experiments, simulations, criteria-based analysis, theoretical arguments and mathematical proofs; while the latter includes methods like surveys, field studies, case studies and action research (Helfert et al., 2012). Nevertheless, a deep core of preliminary ideas and guidelines for choosing between these methods is still missing, which lead to emphasize an "evaluation gap" (Venable et al., 2012) that should be filled.

This study used a mixed research design. The argument for the utility, quality, and efficacy of the built ontology has been based on two evaluation methods: survey and a prototypical implementation used in a case study. In this paper, we present the empirical investigation of GenID Ontology based on an online questionnaire developed under SurveyMonkey followed by some interviews. In the questionnaires, the participants were asked to comment on and rate based on a set of 10 criteria (adapted from Hevner et al.'s (2004) guidelines). In the interviews, the participants were asked to provide more detailed feedback on the strengths and weaknesses of the presented constructs and how they can be improved and extended to meet the imperatives of innovation within modern organizations. Figure 5 below provides a summary of the collected data from the conducted online survey:

Based on the results from the questionnaires and interviews, we found that almost $94 \%$ of participants have shown a very broad consensus on the clarity, representativeness and usability of GenID Ontology, while all of them (100\%) completely agree on its relevance. There was also general agreement (more than $81 \%$ ) on the accuracy, purposefulness, novelty and inspiring of the presented semantic representations; as well as its easiness of understanding and utility. Whereas one participant objected to the clarity, easiness of understanding and utility of this representation and argued that it should be more detailed and simplified in a manner that it can be commonly used and understood by non-experts.

As a result, the performed experiment has delivered proof for usefulness and relevance of GenID Ontology and its components. Theses constructs should be extended with more detailed taxonomies, conceptual models and practical tools to enable a better understanding for non-experts. This task 
could be done in an easy and flexible way thanks to the modular design of GenID Ontology.

\section{GenID Semantic Representation}

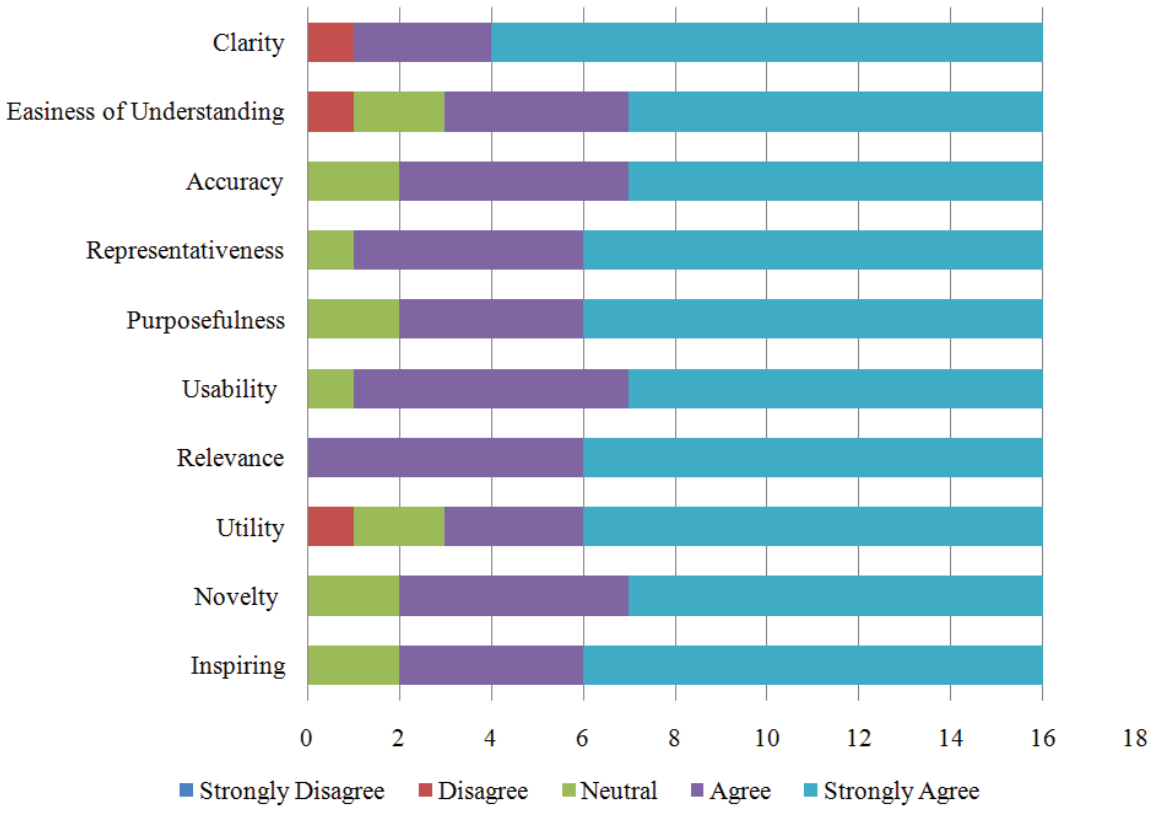

Figure 5. Results of Online Survey about GenID Ontology

Otherwise, although 16 subject matter experts participated in our online survey, this number -while statistically representative from a qualitative perspective- is thinly spread across the delivered constructs. Therefore, the collection of additional data is required before data saturation can be reached and purposeful data analysis can be conducted. To address this limitation, a new set of surveys (questionnaires and interviews) will be conducted to test and validate the deliverable of our research work in different contexts. Besides, and in order to expose the benefits of GenID Ontology and show to what extent it can practically facilitate innovation structuration and management, an in-depth case study has been conducted and will be the subject of an upcoming publication.

\section{CONCLUSION}

In this paper, we introduced the new concept of "innovation interoperability" and presented GenID Ontology, a new and generic representation of the 
innovation knowledge domain, through a modular semantic model covering the interlinked dimensions that we identified as cornerstone for any successful innovation initiative within an open context, which are: 1) Core-Ideas, 2) Actors and 3) Context. These constructs constitute a first step towards developing a theory of innovation interoperability, and form the basis of a generic framework for innovation designing that can be integrated into a multitude of contexts. So, in a future work, they can be contextualized to represent collaborative relations between different innovation actors, and be extended to identify changing roles and emerging tasks within organizations and communities. Further work will be made to use GenID Ontology for similarity detection, clustering, networking and recommendation of relevant innovation entities (i.e. core-ideas, actors and contextual conditions). Another extension of this work would be to develop a custom annotation model to capture and visually represent complex innovation processes. These annotations could also be used for innovation assessment, performance measurement and metrics development. Yet, the introduction of new elements to GenID Ontology will make the annotation process difficult. So, potential future lines of research in this case could be to extend the ontology and add new concepts in a fully automatic way. A related line of extension is to verify related terms' ambiguity and validation. In another line, an online innovation dictionary could be defined and expanded to include a large number of terms and descriptions, in order to reduce terms' ambiguity and enable the development of interconnected competency assessments, learning modules and performance workflows. On the other hand, the performed experiment has delivered proof for usefulness and further experiments with specific and large use cases in both industry and academia are planned.

\section{References}

Amabile, T. M., Conti, R., Coon, H., Lazenby, J., \& Herron, M. (1996). Assessing the work environment for creativity. Academy of Management Journal, 39(5), 1154-1185.

Baron, J. N., \& Kreps, D. M. (1999). Strategic Human Resources: Frameworks for General Managers. New York: Wiley.

Berners-Lee, T., Hendler, J., \& Lassila, O. (2001). The Semantic Web. Scientific American, May, 28-37.

Cañibano, C., Encinar, M. I., \& Muñoz, F. F. (2006). Evolving capabilities and innovative intentionality: Some reflections on the role of intention within innovation processes. Innovation, 8(4-5), 310-321.

Chesbrough, H. (2003). Open Innovation: The New Imperative for Creating and Profiting from Technology. Harvard: Harvard Business School Press. 
Chesbrough, H., \& Brunswicker, S. (2013). Managing open innovation in large firms. Garwood Center for Corporate Innovation at California University, Berkeley in US \& Fraunhofer Society in Germany.

Davila, T., Epstein, M. J. and Shelton, R. (2006). Making Innovation Work: How to Manage It, Measure It, and Profit from It. New Jersey: Wharton School Publishing, Pearson Education Inc.

De Spiegelaere, S., Van Gyes, G., \& Hootegem, G.V. (2012). Job design and innovative work behavior. Journal of Entrepreneurship, Management and Innovation, 8(4), 5-20.

El Bassiti, L., \& Ajhoun, R. (2014). Semantic representation of innovation, generic ontology for idea management.JournalofAdvanced Management Science, 2(2), 128-134.

El Bassiti, L., El Haiba, M., \& Ajhoun, R. (2017). Generic innovation designing -GenID- framework: Towards a more systematic approach to innovation management. Proceedings of $18^{\text {th }}$ European Conference on Knowledge Management (pp. 1097-1106). Barcelona, Spain, 7-8, September.

Fox, M. S., Barbuceanu, M., Gruninger, M., \& Lin, J. (1998). An organisation ontology for enterprise modeling. In M. Prietula, K.Carley \& L. Gasser (Eds.), Simulating Organizations (pp. 131-152). Menlo Park, CA: MIT Press,

Griffin, A. (1997). PDMA research on new product development practices. Journal of Product Innovation Management, 14(6), 429-458.

Gruber, T. R. (1995). Toward principles for the design of ontologies used for knowledge sharing. International Journal of Human-Computer Studies, 43(5-6), 907-928.

Gruber, T.R. (2007). Ontology of folksonomy: A mash-up of apples and oranges. International Journal on Semantic Web and Information, 3(2), $1-11$.

Helfert, M., Donnellan, B., \& Ostrowski, L. (2012). The case for design science utility and quality-Evaluation of design science artifact within the. Systems, Signs \& Actions, 6(1), 46-66.

Hevner, A., March, S., Park, J, \& Ram, S. (2004). Design science in IS research. MIS Quarterly, 28(1), 75-105.

Kolovski, V., \& Galletly, J. (2003). Towards e-learning via the semantic web. In Proceedings of the $4^{\text {th }}$ International Conference on Computer Systems and Technologies (pp. 591-596). Sofia.

Kozioł-Nadolna, K. (2016). Funding innovation in Poland through crowdfunding. Journal of Entrepreneurship, Management and Innovation, 12(3), 7-29.

Lawson, B., \& Samson, D. (2001). Developing innovation capability in organizations: A dynamic capabilities approach. International Journal of Innovation Management, 5(3), 377-400.

Lee, A. S. (2001). Editorial. MIS Quarterly, 25(1), iii-vii.

May, M. (2007). The Elegant Solution. New York: Free Press. 
Ortt, J. R., \& van der Duin, P. A. (2008). The evolution of innovation management towards contextual innovation. European Journal of Innovation Management, 11(4), 522-538.

Pagano, P., Candela, L., \& Castelli, D. (2013). Data interoperability. Data Science Journal, 12, 19-25.

Peffers, K., Tuunanen, T., Rothenberger, M. A., \& Chatterjee, S. (2007). A design science research methodology for information systems research. Journal of Management Information Systems, 24(3), 45-77.

Salter, A., \& Alexy, O. (2013). The nature of innovation. In M. Dodgson, D. Gann \& N. Phillips (Eds.), The Oxford Handbook of Innovation Management. Oxford: OUP.

Studer, R., Benjamins, V., \& Fensel, D. (1998). Knowledge engineering: Principles and methods. IEEE Transactions on Data and Knowledge Engineering, 25(1-2), 161-197.

Venable, J. R. (2006). A framework for design science research activities. In Proceedings of the Information Resource Management Association Conference, 21-24 May, Washington, DC, USA.

Venable, J., Pries-Heje, J., \& Baskerville, R. (2012). A comprehensive framework for evaluation in design science research. In K. Peffers, M. Rothenberger \& B. Kuechler, (Eds.), Design Science Research in Information Systems, Advances in Theory and Practice (pp. 7286, 423-438). Berlin/Heidelberg: Springer.

Zittrain, J. (2008). The Future of the Internet and How to Stop It. Yale: Yale

\section{Others} University Press.

Accenture with G20YEA. (2015). Harnessing the Power of Entrepreneurs to Open Innovation.

Directive 2009/24/EC of the European Parliament and of the Council of 23 April 2009 on the legal protection of computer programs. Official Journal of the European Union.

\section{Abstract (in Polish)}

W okresie wzmożonej złożoności organizacje zmierzajq ku otwartej innowacji. Wspótczesne systemy zarzqdzania innowacjami muszq zajmować się rozproszonymi, heterogenicznymi i szybko rozwijajq̨cymi się cechami wiedzy, które sq dostępne w różnych formach i sq raczej słabo zorganizowane. Ponadto coraz większy stopień specjalizacji i wspótzależności pomiędzy i wewnq̨trz organizacji wymaga wspótpracy grupowej na poziomie organizacyjnym w celu współdziałania z innymi, aby produkować nie tylko nowatorskie, ale także krytyczne innowacje. Jest to sedno tego artykułu, który wprowadza nowa koncepcje "Interoperacyjność innowacyjności”. Następnie formalizuje i reprezentuje semantycznie kluczowe pojęcia, które leżq u podstaw systematycznego podejścia do innowacji i relacje między nimi, poprzez Generalnq Modułowq Ontologię, którq nazwaliśmy "GenID Ontology". Ten ostatni składa się z trzech wzajemnie połaczonych sub-ontologii, odnoszqcych się do kluczowych wymiarów udanej innowacji w otwartym otoczeniu, którymi sq: Core-ideas, Actors and Context. W tym do- 
kumencie przyjęto mieszanq strategię badawczq i wykorzystano jakościowq ankietę online w celu zbadania dostarczonych konstruktów.

Słowa kluczowe: interoperacyjność innowacji; zarzqdzanie pomysłami i innowacyjnościq; ontologia; semantyka; ankieta online.

\section{Biographical note}

Lamyaa EL BASSITI is a Full Ph.D. student at the University Mohammed V in Rabat, Morocco and an associate member of the International Association for Knowledge Management -IAKM. Her main teaching and research interests lie in the areas of smart organization; innovation management, structuration, interoperability and performance; as well as KM. She has published articles on these topics in journals and conference proceedings. 